This PDF is a selection from a published volume from the National Bureau of Economic Research

Volume Title: Social Security Pension Reform in Europe

Volume Author/Editor: Martin Feldstein and Horst Siebert, editors

Volume Publisher: University of Chicago Press

Volume ISBN: 0-226-24108-4

Volume URL: http://www.nber.org/books/feld02-2

Conference Date: March 20-21, 2000

Publication Date: January 2002

Title: Labor Mobility, Redistribution, and Pension Reform in Europe

Author: Alain Jousten, Pierre Pestieau

URL: http://www.nber.org/chapters/c10670 


\title{
Labor Mobility, Redistribution, and Pension Reform in Europe
}

\author{
Alain Jousten and Pierre Pestieau
}

\subsection{Introduction}

The future of the public pension systems in the European (EU) is presently a widely discussed topic. Unfortunately, the debate can be qualified as a rather shallow one, because it addresses only a limited number of questions. In the United States, on the other hand, a great deal of writing - some of it quite influential - is devoted to the old age crisis even though the crisis there is much less severe than in most of the member states of the EU. To understand this statement, one should keep in mind that compared to the majority of European countries, the United States devotes considerably less resources to unfunded public pension systems. Also, U.S. Social Security - the main public retirement program - can rely on a non-negligible trust fund. Furthermore, private funded pension schemes are widespread, and people generally retire at a much higher effective retirement age. Even the most pessimistic forecast of the finances of the U.S. Social Security program seem rosy relative to what can be reasonably expected in a number of European countries. In that respect, Aaron (Aaron and Shoven 1999) notes that "even if no legislative changes were made, 70 to 75 percent of benefits provided under current law could be paid indefinitely," and adds, "To suggest that social security is in crisis is to engage in Orwellian doublespeak" (55). One surely could not write that about most EU countries.

On the issue of the viability of the public systems, European economists and politicians can be classified into two broad categories: those who

Alain Jousten and Pierre Pestieau are both professors of economics at the University of Liège.

The authors are grateful to M. Burda and H. Siebert for helpful comments. 
think that the present systems are more or less fit for the future, and those who think that we are heading for serious financial trouble - if not in the short, at least in the medium run. On the face of this opposition, there seems to be little common ground between the two groups. However, most of the analysts seem to agree on at least one issue, namely, the neglect of individuals' mobility under future pension systems. Usually, critics tend to consider the future of an isolated pension system or, at best, of a given country's multiple systems while ignoring or underestimating the potential for increased intercountry and intersystem mobility. In so doing, the critics neglect an entire spectrum of issues that have the potential to induce large changes in the returns individuals can expect from their pension contributions. Furthermore, the consequences for the public systems themselves are also far from negligible.

In this paper, we discuss the main characteristics of European mandatory pension systems and the implications of increasing factor mobility for these systems. Although it is undoubtedly true that labor mobility between countries is rather limited, it is more than likely that it will increase. In the past, individuals' mobility was inhibited not only by cultural and language differences, but also (to a non-negligible extent) by regulatory and legal limitations. At present, these limitations on job mobility are being dismantled in the wave of reduction of public intervention and the creation of a true single European market. Obvious exceptions are some government jobs that we could call "strategic," as well as occupations in the legal profession. Cultural and language barriers are also becoming less relevant as people are exposed more frequently to foreign languages and cultures from a very young age.

The results of these changes can already be felt today, particularly in some segments of the workforce. For example, young college and university graduates are more mobile than their less-educated counterparts, for multiple reasons. First, they generally have better language training and more frequent exposure to other cultures (e.g., through the Erasmus and Socrates student exchange programs of the EU). Second, they generally hold jobs that are easier to relocate, due either to the characteristics of the job itself (e.g., a computer programmer telecommuting to work) or to an international working environment (e.g., a customer support machine-tool specialist with a European or even worldwide customer base). ${ }^{1}$

Hence, we must study not only the question of whether labor mobility will increase and thus will have an impact on the viability of the pension systems, but also the question of whether this mobility will continue to evolve differently for different population segments, and what the consequences of such an evolution will be.

In the present paper, we focus on the issue of mobility at the beginning

1. On the contrary, immigration from outside the EU tends to cater to unskilled workers (but this is not the concern of this paper). 
of the working life. The questions we are mainly interested in are whether there is room for strategic relocation of individuals at the beginning of the working life, and whether such mobility has the potential to change the redistributive patterns (both inter- and intragenerational) of the various national pension systems.

Relocating at the beginning of the working life is not the only kind of mobility with implications for social security. A worker can relocate in the middle of the working life, and the portability of social security and other pensions schemes can foster or (more probably) restrict this type of mobility. One may also relocate at the end of one's working life. Retirees may be attracted to warmer weather or cheaper living expenses and accordingly move to another country. This type of mobility may have some consequence on public revenue, depending on the tax structure. Finally, there is the cross-border mobility, which occurs when an individual works and lives in two adjacent countries. We will also deal with these alternative types of mobility.

The structure of the paper is as follows. In section 3.2 we illustrate some of the core features of European pension systems and compare them to those of the United States when useful. We also discuss some issues relating to mobility in the middle and at the end of the working life. In section 3.3, we present some insights into which paths European governments can take toward reform. Section 3.4 represents the main thrust of the paper and deals with the direct implications of labor mobility on various provisions of pension systems. We use findings from the literature on fiscal federalism to illustrate some of the potential effects of mobility. Section 3.5 addresses the types of mobility within the life cycle other than that at the beginning of the working life. Finally, we conclude the paper with some comments in section 3.6.

\subsection{Characteristics of the European Pension Systems}

Before proceeding further, we must note four points that are worth emphasizing. They pertain to the differences between pension systems in the Federal United States and the Confederal EU. First, compared to the U.S. federal social security structure, pensions in the EU are the responsibility of national governments. Second, within the EU, there are important differences in the size and the organization of pension schemes across countries. Third, in the whole debate over the future of social security in the United States, the scope is limited to the national borders. In the EU, there is a well-founded concern that economic and political integration affects the survival prospect of each national pension system. Finally, labor mobility is known to be negligible within the EU; even within each national entity, interregional mobility is lower than across states in the United States.

The first and fundamental pillar of European pension systems is manda- 
tory and unfunded. The systems are organized under the form of a payas-you-go (PAYGO) defined benefit scheme. Individuals contribute to the scheme today; in return they receive benefits when retired that are financed by future generations' contributions and based on some pension computation formula that is not necessarily a function of past contributions. Differing system characteristics across EU countries are their size and their redistributiveness. For example, the French and German systems are more than twice as important as the British system in terms of their share of gross domestic product (GDP) — close to 13 percent each, as opposed to 5.5 in the United Kingdom. ${ }^{2}$ Furthermore, although in some countries these systems account for a large fraction of the total income of the elderly, in other countries they do not (see Disney and Johnson 2001).

Not surprisingly, the second pillar (occupational pensions) is quasiinexistent in the countries that have a very strong first pillar; the same is also true of arrangements belonging to the third pillar (individual retirement savings). More generally, it is fair to say that the presence of private pension arrangements is an inverse function of the generosity of the public system. In the absence of public provision, individuals must try to secure their old age income through private market arrangements, be they compulsory or discretionary.

As opposed to the public PAYGO systems, occupational pensions are generally organized on a fully funded basis. A notable exception are the French unfunded second-tier pensions, which are both defined benefit and based entirely on a PAYGO principle, and hence belong to the first rather than the second pillar. Another characteristic of occupational pension plans is that they can be either defined benefit (DB) or defined contribution (DC), in which the pension is a direct function of past contributions. Third-pillar schemes, in turn, are generally fully funded and based entirely on DC basis.

From the point of view of redistribution, public pension systems are markedly different among the various EU countries. Two main levels of redistribution must be distinguished. The PAYGO nature of European public pension systems has lead to what is known as the free lunch given away to past and current generations of retirees. This free lunch implies an implicit government debt, the so-called social security wealth, which is particularly high in countries with generous pension schemes. In Germany and in France, this implicit debt is much higher than the explicit government debt. The French ratio of debt to GDP is just below the Maastricht ceiling of 60 percent. If the implicit government debt is added in, the overall ratio amounts to about 160 percent (Roseveare et al. 1996). This redistribution from younger to older generations clearly varies across European countries and is not without consequences as factor mobility increases.

2. The corresponding figure for the public Social Security retirement program in the United States is 4.6 percent. 
Another source of variation across European countries is the extent of intragenerational redistribution. In some countries there is a tight link between contributions and pension benefits according to the insurance principle of getting an actuarially fair return. In some other countries this link is loose. Indeed, in countries (such as France and Germany) with contribution-related benefits, social security does not effect any redistribution; one sometimes speaks of a Bismarckian regime. On the contrary, in countries with redistributive benefit rules the replacement ratio declines as income increases. In these countries (such as the Netherlands or the United Kingdom), workers truly consider that their contributions are like taxes-namely, that the contributions do not entitle them to an equiproportionate benefit.

Intragenerational redistribution can take on different forms, however; for example, early retirement provisions can also cause major redistribution of income. Indeed, in countries such as Belgium, where implicit taxes on continuing work beyond the time of first eligibility for early retirement benefits is close to 80 percent, the system operates a clear redistribution toward individuals' retiring early (Pestieau and Stijns 1999).

The effective retirement age also varies across European countries. It is indeed striking to observe that in Europe, the current and expected demographic parameters are not terribly divergent. The statutory retirement ages are also quite similar. What varies more is effective retirement. To capture this notion, Gruber and Wise (1999) have introduced the concept of unused labor capacity between the ages of fifty-five and sixty-five. This capacity ranges from 67 percent for Belgium to 35 percent for Sweden (it is 37 percent in the United States and 22 percent in Japan). This is due mainly to a number of both implicit and explicit incentives to early retirement (so-called "actuarial" adjustments), which vary wildly among European countries. These incentives are pervasive in the social security programs of countries such as Belgium, France, Italy, and the Netherlands, where the effective retirement age is quite low.

Furthermore, some European countries have essentially opted for a universal national pension system, whereas others have preferred to set up multiple systems. As a consequence, the study of the question of inter- and intragenerational redistribution finds itself complicated by the sometimes quite opposing degrees of redistribution of the various national systems.

Altogether, the result of these features is that in most EU countries, elderly households experience an unprecendented standard of living relative to the other age groups and relative to the past. Poverty rates are also extremely low among today's retirees.

\subsection{Reforming the Pension Systems}

We have described the main characteristics of the European pension systems, which appear rather heterogeneous in four respects: size, burden 
on future generations, redistribution across households, and retirement age. These characteristics combined with population aging and declining productivity growth explain the old age crisis that is clearly more acute in countries with generous schemes. Until now, each national government has more or less successfully addressed this crisis. In Cremer and Pestieau (2000), it is argued that the old age crisis does not come solely from the combination of demographic aging and PAYGO schemes. By appropriately adjusting the key parameters of social security systems (namely, the replacement rates, the payroll taxes, and the retirement age) while fostering individual or collective saving for retirement, governments can avert the old age crisis. The real issue is also and mainly political. Reforms must go through the political process, in which majority voting and vested interests too often make impossible the implementation of reforms otherwise optimal from the standpoint of both intra- and intergenerational equity.

In that respect, two remarks are in order. In countries that have undertaken reforms, the approach has been to rely on the grandfathering formula, precisely to circumvent paralyzing interest groups. This can have an unbearable cost. Furthermore, it is well admitted that a total shift from PAYGO to a fully funded system is not feasible. If the transition generation is to be compensated for abandoning PAYGO by issuing an appropriate public debt, and if the benefit rule is unchanged so as to keep the extent of intragenerational redistribution constant, then such a shift would be neutral. The government that would undertake such a reform would run an increased deficit, which would be exactly offset by the increase in private savings from the surplus of the new pension plans. The national saving rate would not increase. In effect, the reform would simply convert an implicit obligation of the government to future retirees into explicit debt. That said, most reforms, whether implemented or contemplated, include the development of some fully funded schemes acting as supplement (and not a substitute) for the existing PAYGO first pillars.

Discussion of the viability of existing pension systems and alternative ways of reforming them is most often conducted in the setting of national borders with no or low labor mobility. The implicit assumption is that although physical capital has proven to be quite mobile, labor may not be so mobile. Language is often the most often-cited barrier to migration, but differing customs, traditions, and preferences matter as well. Governments themselves may implement policies that inhibit labor mobility: regulation of house prices and rents, subsidies of declining industries, residency linked social benefits. Inefficient property markets make moving an expensive proposition. One expects that these various barriers to mobility will progressively fall under the specific pressure of European integration and the more general pressure of economic globalization. It is therefore relevant to investigate the implications of labor mobility for the old age crisis.

We thus have an interesting question, namely, whether a shift from 
PAYGO to fully funded systems has any effect in the face of increasing labor mobility. As already noted before, a "neutral" shift from a PAYGO to a fully funded system has no effect in the absence of mobility. The same proposition implies that, if before the reform there is what we call a migration equilibrium, after a neutral reform, this equilibrium is unchanged. Any individual will face the same lifetime utility before and after the reform; there are thus no reasons for moving.

Clearly, if the reform is not perfectly neutral from the viewpoint of interor intragenerational redistribution, then a migration equilibrium will result according to the argument developed in the next section. If the reform does not fully compensate the transition generation of retirees, the young generation of workers will face a lighter liability in the reform country (through lower implicit or explicit government debt). Retirees cannot move out but workers from other countries can be attracted by the reform country and move in. Hence, the changing intergenerational redistribution patterns induce mobility. Furthermore, recall that before the reform any individual worker was indifferent between staying in his or her home country and moving to the reform country. If the reform does not restitute the same redistributive pattern as that prevailing before (i.e., if it does not reduce the amount of intragenerational redistribution), high-wage workers can be attracted to move to the reform country and low-wage workers to move out of it.

\subsection{The Implications of Labor Mobility in the European Union}

As announced, we now turn to the expected effects of labor mobility on the way countries organize their social security systems. As already mentioned, we realize that we are far from smooth mobility across EU countries, although we believe that this will eventually be achieved. In any case, in a competitive market economy, capital mobility implies equalized rates of return and hence equality of wages for a given skill level. Yetand this is important for the problem at hand-there is a difference between equal wage rates and equal lifetime utilities. That difference may arise from different factors, notably national indebtedness and unfunded pension systems that may benefit households when introduced and burden them thereafter.

We consider autarkic countries, each having its own specific pension policy, and see what happens when we allow for factor mobility. Two settings can be envisioned. In the first, countries are passive; they do not want to change their approach to financing (PAYGO vs. fully funding), the role of supplementary pension, or the type of benefit rule (Bismarckian or Beveridgean). As shown by Cremer and Pestieau (2000) in a two-country model, such passive behavior can have a pathological outcome, with all high-income individuals or all low-income individuals conglomerating in 
one country, depending on which group is mobile. In the second setting, countries react to migration and reform their pension systems according to their planners' social welfare function or through the political process.

We will adopt the latter setting and assume that each country has a social planner with a utilitarian objective. This seems to be the prevailing assumption in the literature. First we look at the effect of mobility on the intragenerationally redistributive dimension of pension provisions, and then at the effect of mobility on the intergenerationally redistributive dimension, namely, the size of the social security wealth.

\subsubsection{Intragenerational Redistribution}

The prevailing view is that a redistribution policy is best administered by the central government, in our case the EU. Accordingly, decentralized redistribution policies cause some kind of adverse selection. In a world of perfect mobility, we would expect individual countries with redistributive programs to attract poor households from less-redistributive neighboring countries and to repel rich households who must pay for the programs. These reactions eventually make it impossible to pursue any redistribution at the national level except through some kind of cooperation among the member states. We expect these general predictions to hold even in the presence of a limited mobility of individuals belonging to some income and social groups.

The canonical model used is naturally simple. It involves two countries producing an output using two types of workers, skilled and unskilled. Skilled workers are assumed to be mobile and unskilled workers are immobile (the opposite assumption does not change the resulting conclusion). There is a social security scheme that affects some redistribution between the two types of individuals. In the absence of mobility, each country implements the redistribution that fits its welfare criterion. When there is mobility, such a policy is bound by the constraint that the lifetime utility of mobile workers be identical. In other words, any move toward a more generous system in a country attracts migration from the other countries.

In the literature (Cremer, Fourgeaud, et al. 1996; Wellisch 2000) one usually contrasts redistributive social security conducted both without and with coordination. The former case reflects the current step of the EU; the latter a still far-fetched possibility. Three findings are standard. First, uncoordinated national redistributive policies result in migration distortions when countries are different. In other words, the efficiency required so that the marginal productivity of mobile workers be equated is violated; a corollary to this finding is that if one country values redistribution more than the other, it will end up with relatively less-skilled workers and less redistribution than in autarky. The second finding is that if both countries are identical in all respects, the equilibrium is symmetric and the allocation 
of mobile workers efficient; yet the suboptimal degree of redistribution remains. The third finding is that a coordinated increase in the redistributive payroll tax rate in the two regions increases social welfare. Note that the same conclusion holds if mobility is only partial. The only case in which mobility is neutral is that of an actuarially fair pension system.

\subsubsection{Intergenerational Redistribution}

Let us now look at differences in social security wealth, or, expressed differently, in intergenerational redistribution. The issue is the same as that of different levels of public debt. The Maastricht Treaty introduced a ceiling of 60 percent on the ratio of debt to GDP and adopted a narrow definition of public debt. It is clear, however, that the reasons that led to adopting that ceiling apply as well to the implicit debt generated by generous PAYGO pension systems. The major reason for imposing such a ceiling was the Economic and Monetary Union (EMU), which is independent of whether there is labor mobility. The rationale is simple: When a country deeply endebted through standard debt or through PAYGO social security joins a fully integrated economic union, it makes its partners partially pay for it.

If there is labor mobility, differentials in the net benefits that individuals can expect from public pensions along with other policies alter the payoff to migration and can influence the international allocation of labor. Wildasin (1999) estimates the change in the present value of lifetime wealth that results from switching from one public pension program to another for representative workers in seven EU countries. He shows that moving between certain countries can result in an increase of 15 percent or even more in lifetime wealth. As he points out, differentials in net benefits create fiscal incentives for inefficient labor allocation. We expect increased mobility to lead to a reduction in differences in intergenerational redistribution over time.

Consider two countries, identical in all respects, that contemplate adopting a PAYGO system for, say, compensating the current generation of retirees for hardship that prevented them from saving for retirement. It is clear that with mobility of the young generation, there will be a "race to the bottom," namely, toward a lower amount of such pension provision than decided in autarky. Naturally, we assume that the young generation anticipates that a PAYGO system relative to a fully funded system implies a cost that depends on the gap between the rate of return on capital and the rate of growth of the economy.

Consider an equally realistic setting in which two countries are identical in all respects but toward intergenerational redistribution. One relies more than the other on PAYGO to finance its pension system. What happens when their borders are open to possible migration of the young? One can 
expect an outflow from the more indebted country to the less indebted one. ${ }^{3}$ The only way this outflow can be stopped is by decreasing the burden of such a debt, and this implies taxing the currently retired and immobile generation. Note that if on top of this, the population is aging and hence the dependency ratio is going up, so there is an additional incentive for the young generation to move out from PAYGO countries to fully funded ones.

As a consequence, countries with a population dedicated to the PAYGO principle and willing to resist even partial shifts toward fully funded schemes can be forced to reform their systems because of the mobilityinduced tax competition.

Finally, let us analyze the implication of differences in retirement ages in European countries once we allow for increased labor mobility. Exactly as for the degrees of intra- and intergenerational redistribution, we would expect increased mobility to render social security systems less redistributive with respect to retirement age. By this, we do not understand that retirement ages will necessarily tend toward one identical age of retirement all across the EU. Rather, we would expect there to be a schedule of retirement ages and benefit packages that people of different survival probabilities could choose from. For example, early retirement would go together with reduced benefits, late retirement with increased monthly benefits. Individuals would then select the best package for themselves, depending on their own estimates of the survival probabilities they face.

\subsubsection{Is There a Race to the Bottom?}

In the two previous subsections, we have argued that with some factor mobility there would be convergence toward less spending on PAYGO provisions and less redistribution in retirement benefits. This expected evolution, often labeled a "race to the bottom," thus concerns PAYGO and flatrate benefit systems. Do we witness such a race to the bottom?

When looking at the evolution of old age benefits (aggregate or perbeneficiary) over the last decades, it is surprising to see that they have not decreased in most EU countries. During the 1990-96 period, the ratio of old age benefits to GDP has increased everywhere but in the Netherlands. Does that mean that the danger of social dumping in the area of social security is not to be taken seriously? Not really. This question calls for a number of qualifications. First, it is possible that there are some lags in the reaction of mobile agents to increased mobility. Second, the cost of mobil-

3. This issue has lately received much attention. See Bräuminger (1999), Pemberton (1999), Meier (2000), Crettez, Michel, and Vidal (1996). If national governments are passive and the only factors of production are mobile labor and mobile capital, then the more indebted country disappears. To avoid such an extreme solution, one must introduce fixed factors such as land or real estate. Alternatively, one must allow for national government action toward a rapid reduction in the national debt or the PAYGO pensions at the expense of the immobile retirees. 
ity might be higher than is often thought, and might not be restricted to the language issue or the financial cost of moving. The job market is still relatively closed. More importantly, the same reasons that explain why each country adopted a given type of social security (PAYGO or fully funded, Bismarckian or Beveridgean) can explain why people do not move. It is possible that they are attached to particular type of social protection, and in that respect, they are not as opportunist as assumed in models of fiscal competition. This point holds only for the mobility of net contributors and not for that of those benefitting from redistribution. Also, it noteworthy to consider recent work that identifies previously unrecognized beneficial effects of competition among governments. It can be shown that with imperfect competition (Wilson 1999) or with majority voting (Cremer and Pestieau 1998), public spending and redistribution can very well not decrease as a result of factor mobility. Finally, it is interesting to note that countries that redistribute intragenerationally quite often do not rely exclusively on PAYGO systems. The converse holds true for countries that do not redistribute intragenerationally. Hence, the two redistributive effects would offset each other.

These different arguments may explain why the effects of mobility on redistribution have so far been limited. It is, however, important to realize that in the future they can loose their strength. For example, the impediments to mobility induced by fiscal or social policies are likely to disappear in the future with the integration not only of European economies but also of national mentalities and cultures.

\subsection{Mobility within the Life Cycle}

In the previous sections, we implicitly assume that individuals contemplate migration at the beginning of their life cycles. At that early stage, they are supposed to be able to weight the pluses and minuses of alternative locations. In the real world, there are other types of mobility; workers can move within the working period or at the beginning of the retirement period. Exactly as for mobility at the beginning of the working life, such relocations can be triggered by factors pertaining to job offers on hand, family matters, health conditions, and health coverage - which are factors exogenous to the social security system - or, alternatively, by strategic considerations created by the social security system itself.

\subsubsection{Mobility at Retirement}

First we consider mobility at the beginning of the retirement period. Both public and private retirement schemes all across the EU allow individuals to receive their social security benefits independently of their place of residence in the EU, and sometimes even far beyond the reaches of the Union. In this respect, it is indeed not uncommon to observe retirees 
relocating from Germany or Sweden to Spain or Italy after retirement, be it for health reasons or simply because they want to see the sun. This is not uncommon but surely is not as widespread as in the United States (think of the situation currently observed in both Florida and Arizona). If a large number of retirees from Nordic countries would settle in southern countries, there would be a loss in the tax base for the former and a gain for the latter. This is so because the elderly essentially are taxed indirectly rather than directly. It is indeed well known that social security income is not as heavily taxed as labor income. Furthermore, interest income is hardly taxed in the EU. Value-added tax thus is frequently the only major source of tax income from the elderly. This effect on the tax base would be reinforced by the presence of differential mobility according to income. It is more than likely that the people moving south would have a higher average income than those staying behind in the north. Hence, this reduction of the tax base in northern countries would also be accompanied by a shift in the overall tax burden from the old to the young and from the rich to the poor, with all its consequences on the mobility of the young.

This finding is underlined when we introduce the welfare component of public pensions benefits - namely, means-tested old age benefits - into the picture. Eligibility for this type of income is based strictly on a residency criterion. Therefore, assuming a more generous system of means-tested benefits in the north of Europe, we would expect poor people to move north as a reaction to the more generous social security system. Again, this condition assumes that national governments do not react. Expectedly, they will not remain passive and will adjust their welfare systems and their tax structures to counter unpleasant effects of retirees' mobility.

\subsubsection{Mobility during the Working Period}

Turning to the concept of mobility within the working period, we must introduce several distinctions. First of all, we must distinguish the first from the second and third pillars. Second, we also must distinguish mobility concerning the workplace from mobility concerning the place of residence; here we consider the latter. Shortly after the Treaty of Rome, member states began to develop a system of multilateral coordination for social insurance legislation. ${ }^{4}$ The coordination so achieved was aimed at establishing equality of treatment between nationals and nonnationals (but belonging to the EU) in social insurance. This has proved successful because it allows individuals to take up residence or employment in any country of the EU without undue loss of social insurance rights - that is, without being at significant disadvantage, compared with those who remained in their own countries throughout their entire working lives. This system of multilateral coordination applies to pension provisions, but only to the first pillar. When this system was developed, it was believed that, at a later

4. This is enacted through Regulation 1408/71 and 574/72; see EC (1994). 
stage, a parallel multilateral scheme of coordination would eventually be put in place for supplementary pensions, whether based on legislation or on contractual arrangements. However, it quickly turned out that it was not easy to overcome the obstacles to freedom of movement posed by the pattern of existing supplementary pensions in the EU, which are both complex and diversified. Patterns are complex in the sense that even within a given country, there is a large diversity of pension schemes that are often interwoven with particular rules of the tax code. Furthermore, tax treatment of pensions is not necessarily stable, and thus introduces a high level of segmentation. The system is also diversified in the sense that, in some countries, private supplementary pensions represent the bulk of the pension rights of individuals, whereas in other countries they represent only a trickle. The distinction between defined benefit (DB) schemes and defined contribution (DC) schemes is also important here, because it is much easier to transfer balances of DC plans rather than accumulated pension rights in DB plans.

Over the last three decades, the Commission (as well as the private sector, the insurance industry, and the pension fund industry) have searched for some solutions, but obstacles remains today and hence freedom of movement of workers covered by supplementary pensions is restricted. For our purpose, the implication is clear: There is more freedom between countries with dominant mandatory social security plans than between countries with mixed arrangements. Let us add that in the latter, the first pillar is sometimes means-tested, implying that residency restrictions exist even after retirement (as already mentioned).

It is clear that when considering a pension system (both first and second pillars) that does not slow mobility, it is tempting to generalize DB approaches. In the first pillar, this would be made possible by adopting the so-called "national accounts pension system" that is now used in Italy and Sweden. Such a policy would clearly facilitate labor mobility in particular within an enlarged EU. Indeed, with a more and more heterogeneous economic union, the current arrangements concerning mandatory systems could become increasingly difficult to implement. At the same time, it is clear that a generalized move toward DC systems makes them less redistributive - a serious problem that assistance programs (means-tested minimal pensions) can solve only partially.

\subsubsection{Cross-Border Mobility}

We now turn to a frequently neglected issue related to mobility during the working life. Indeed, we must distinguish the mobility of workers with respect to their places of work from that with respect to their places of residence. ${ }^{5}$ In Belgium, for example, the rules of the public social security

5. The first type of mobility is qualified as travail frontalier in French (i.e., people crossing the border to get to work). 
program (the non-means-tested benefits) are not neutral with respect to the place of residence. Indeed, for workers changing both the residence and the place of work, the standard EU rules on cross-border mobility apply: The individual accumulates fractions of pension rights in different countries according to the proportion of his or her professional career spent contributing to a given system. Consider the case of a worker who instead of moving his place of residence to another country only commutes to work abroad. In this case, he still generates pension rights abroad in proportion to the time spent in every foreign system. However, in parallel, he accumulates fictive or imputed pension rights in the Belgian social security system: fictive wages - which are close to national average wages are imputed into his Belgian earnings record, independently of the real observed earnings of the individual. If, at the time of retirement, the foreign pension is smaller than the fictive Belgian pension corresponding to the same period of time, the Belgian social security system then pays the difference to the individual. Hence, the Belgian system illustrates that it is possible to introduce an additional margin for maneuvering, namely, a separation of the choice of the residence and the workplace. This distinction is especially important for small countries such as the Benelux countries, where almost anyone can work in a different country than the one in which he or she resides. The same is obviously true for border regions of larger countries.

This particularity of the Belgian system, however, also reemphasizes one weakness of the entire current regulatory framework for mobility: namely, its focus on first-pillar pensions. To illustrate this point in the extreme, consider the case of a Belgian resident working in the Netherlands. At retirement, the worker will have significant Dutch pension entitlements, some large fraction of them under the form of occupational private pensions. However, in its computation of the potential pension complement, the Belgian social security administration does not take the Dutch occupational pension into account and hence pays out a much larger supplement than would have been the case had all kinds of pension income been taken into account.

\subsection{Conclusions}

We began this paper by showing that members of the EU have contrasting pensions systems, particularly with respect to redistribution. Such a setting is likely not sustainable, given factor mobility. Capital mobility that is high and labor mobility that is still negligible (except for highly qualified workers) imply that eventually there will be some convergence toward less redistribution, both between generations and across households. Pension systems, particularly generous ones, face a tough dilemma: adjust or perish.

Having some governments forced to reduce their debt, both explicit and 
implicit, is not a bad thing, particularly in view of the implications of aging for public finances. However, pressure to reduce the redistributiveness of social security, particularly toward low-income retirees, is by no means desirable. Even if the overall level of poverty among elderly people is quite low in the EU, there is a great deal of variability between member countries. One may therefore fear that a race to the bottom on social security benefits will lead all EU countries to experience the higher poverty rates among the elderly that we presently know only in countries such as the United Kingdom or Portugal.

In that respect, the idea of developing a European safety net for the elderly could be seriously envisioned. Indeed, there is little doubt that the elderly are the most vulnerable group of the population. This again raises the crucial question of whether European governments take the social dimensions of the EU seriously. As Atkinson (1995) points out, the main problems limiting individual national governments to provide effective social protection are "those arising from political pressure-a political economy, rather than a migratory, constraint on national policy" (9). One can easily speculate that such political pressure is much stronger at the level of the EU. To put it another way, one has the feeling that a number of national governments use the excuse of fiscal competition to explain their failure to push for effective social protection at both the national and Union levels.

The Maastricht Treaty implied a mandatory reduction of the public debt in countries such as Belgium and Italy. Another interpretation of this reduction is to consider it as a reaction to increasing mobility in Europe. Even if those countries are perhaps unwilling to abolish their PAYGO systems altogether, they still must lower the burden on their young, mobile workers in the face of increasing tax competition.

Two final remarks conclude: First, this paper has focused on labor mobility within the EU. There is an even more challenging mobility, that which results from immigration flows from outside the EU, particularly from Eastern Europe. The reality - or even more so, the potentiality - of these flows is likely to induce individual national government to reform their social security systems toward the insurance principal, with entitlements based on past work and past contributions (see Michel, Pestieau, and Vidal 1998). Finally, even for those concerned by the threat of economic integration on effective social protection, it is crucial to improve the portability of supplementary pension schemes within and across EU countries.

\section{References}

Aaron, H. J., and J. B. Shoven. 1999. Should the United States privatize social security. Cambridge, Mass.: MIT Press. 
Atkinson, A. B. 1995. Incomes and the welfare state: Essays on Britain and Europe. Cambridge: Cambridge University Press.

Bräuminger, M. 1999. Generalized social security finance in a two-country world. Scottish Journal of Political Economy 46:287-302.

Cremer, H., V. Fourgeaud, M. Leite Monteiro, M. Marchand, and P. Pestieau. 1996. Mobility and redistribution: A survey of the literature. Public Finance $51: 325-52$.

Cremer, H., and P. Pestieau. 1998. Social insurance and labor mobility: A political economy approach. Journal of Public Economics 68:397-420.

- 2000. Reforming our pension system: Is it a demographic, financial, or political problem? European Economic Review 44:974-84.

. 2001. Social insurance competition between Bismarck and Beveridge. Unpublished manuscript.

Crettez, B., Ph. Michel, and J.-P. Vidal. 1996. Time preference and labor migration in an OLG model with land and capital. Journal of Population Economics 9: 387-403.

Disney, R., and P. Johnson. 2001. Pension systems and retirement incomes across OECD countries. London: Edward Elgar.

European Commission (EC). 1994. Supplementary pensions in the European Union: Development, trends and outstanding issue. Report by the European Commission's Network of Experts on Supplementary Pensions, Brussels.

Gruber, J., and D. Wise, eds. 1999. Social security and retirement around the world. Chicago: University of Chicago Press.

Meier, V. 2000. Time preference, international migration and social security. Journal of Population Economics 13:127-46.

Michel, Ph., P. Pestieau, and J.-P. Vidal. 1998. Labor mobility and redistribution with evolving altruism: The case of a small economy. Regional Science and Urban Economics 28:363-77.

Pemberton, J. 1999. Social security: National policies with international implications. Economic Journal 109:492-598.

Pestieau, P., and J.-P. Stijns. 1999. Social security and retirement in Belgium. In Social security and retirement around the world, ed. J. Gruber and D. A. Wise. Chicago: University of Chicago Press.

Roseveare D., W. Leibfritz, D. Fore, and E. Wurzel. 1996. Aging population, pension systems and government budgets: Simulations for 20 OECD countries. OECD Working Paper no. 168. Paris: Organization for Economic Cooperation and Development.

Wellisch, D. 2000. Theory of public finance in a federal state. Cambridge: Cambridge University Press.

Wildasin, D. 1999. Public pensions in the EU: Migrations incentives and impacts. In Environmental and public economics, ed. A. Panagariga, P. Portney, and R. Schwab, 253-82. Cheltenham, U.K.: Edward Elgar.

Wilson, J. D. 1999. Theories of tax competition. National Tax Journal 52:269-304.

\section{Comment Michael Burda}

This paper addresses a complex array of issues that has captured the attention of policy makers across Europe. In the domain of pension systems 
and the pension crisis, Europe differs from the United States in obvious ways. First, unlike the United States, Europe does not yet constitute a nation in any practical sense of the word, and probably will not for at least another half-century. Second, although pensions remain a national responsibility, economic integration and labor mobility are already panEuropean phenomena. Labor mobility has a direct impact on the way pensions function and are financed. Third, labor mobility is joined by increasing capital mobility and product market integration as potential mechanisms of economic integration. As Mundell (1957) argued, the latter two are generally substitutes for labor mobility and could, in principle, alleviate if not remove the urgency of labor mobility's threat to Europe's national pension systems.

Jousten and Pestieau describe the pension system of the representative European economy as primarily national pay-as-you-go (PAYGO), by virtue of its strong emphasis of the first pillar (public pensions, which have become increasingly easy to transfer across intra-European Union borders). Company pensions are fragmented and are difficult to vest. The authors' point is that the coming pension crisis in Europe, brought about by the same deteriorating demographics and declining productivity growth observed in the United States, will be exacerbated by heterogeneity in program generosity, burden on future generations, and degree of redistribution due to higher replacement rates and early retirement. The authors argue against a total shift to funded systems on the grounds that it is not feasible. Their main message is that, to the extent that pension reform is not neutral, mobility of labor in Europe may induce severe difficulties on its own. Marginal households will induce a forced convergence or even a race to the bottom among competing nations. This could eliminate redistributional aspects of pension systems, taken by the authors to be a desideratum. A central implication is that pan-European coordination of pension and, more generally, taxation policy is necessary to implement redistribution aims. The point is a familiar one, and applies to all available national mechanisms of redistribution, such as cash transfers and tax credits.

My first remark deals with the empirical, as opposed to the theoretical, relevance of labor mobility in Europe to the pension crisis. Implicit in the discussion is the Roy-Borjas model of mobility, in which heterogeneity of returns to spatial mobility lead agents to "vote with their feet" and choose those economies in which the net return is the largest. Generally, this means that low-skilled workers migrate to countries with generous safety nets and redistributive systems, whereas high-productivity workers migrate away from them. What I missed in the paper is empirical evidence that this is an important phenomenon. How important is (or was) "welfare shopping" in the United States? Using the Roy-Borjas model, one would conclude that European countries with more generous pension systems and social safety nets sow the seeds of their own destruction. However, is 
there enough variance of policies among European countries to induce such behavior? The fact that a number of European nations are parties to the Schengen Agreement without explicit convergence of social policy is evidence that the marginal worker is far from considering the decision to migrate, and the observed flows are too weak to matter. Merely asserting that marginal workers enforce an arbitrage condition is not enough, because a no-profit condition is observationally equivalent to an equilibrium in which no mobility occurs because no one wants to be mobile. Due either to fixed costs or option values of waiting, modern migration theory generally predicts a zone of inaction for wages, within which no migration occurs despite higher lifetime utility abroad; in this case, the marginal analysis, which gives rise to the results referenced by the authors, is of limited usefulness. A good example of this is East-West German migration, which remains a trickle despite a wage gap in 2000 of roughly 25 percent.

The overwhelming empirical evidence suggests that Europeans are immobile. Even in a fully integrated environment, Europeans simply do not move. This is due partly to their current demographic situation: Europeans are older and live in more homogeneous populations. Mobility declines sharply with age. Language differences militate against the migration decision. In addition to these factors, Europeans view local amenities as a strongly normal good, so that the income effect of local prosperity depresses migration considerably (see Faini and Venturini 2000). It is a red herring to attribute Europeans' behavior to institutions. European low mobility derives primarily from preferences, as intranational migration behavior clearly substantiates. In a democracy, economic institutions are a reflection of national tastes.

To illustrate how striking the differences can be, consider table 3C.1, which compares unemployment rates of cities (1995) in Louisiana with those in the Bundesländer (federal states) of Germany (1995). The rather tight homogeneity of rates in the former stands in stark contrast to the variance of the latter, and is remarkable, given substantial averaging-out of local labor market areas in Germany (for the states at least), and given that the public transport infrastructure is much more developed in Germany than in Louisiana.

An interesting question that is left unaddressed by the authors is the extent to which increased immigration from outside the European Union (EU) might change European "traditions." Guest workers are mobile almost by definition; once inside Europe and with the rights of EU citizens, they may become the enforcer of the marginal migrant equilibrium condition described by Jousten and Pestieau. It should be recalled, however, that older labor market participants tend unconditionally to be the least mobile and therefore pose the least threat to the redistributional element described (early retirement).

My second comment concerns the equivalence of product market inte- 
Table 3C.1 Regional Unemployment: German Federal States versus U.S. State of Louisiana, 1995

\begin{tabular}{lc}
\hline Geographical Area & Unemployment Rate \\
\hline German federal states & \\
City-states & \\
Berlin, West & 14.3 \\
Berlin, East & 12.1 \\
Bremen & 14.0 \\
Hamburg & 10.7 \\
Selected states & \\
Bavaria & 7.9 \\
Hessia & 8.4 \\
Mecklenburg-Vorpommern & 16.1 \\
Saxony & 14.4 \\
Schleswig-Holstein & 9.1 \\
Thuringia & 15.0 \\
Average & 9.3 \\
Louisiana & \\
Alexandria & 7.3 \\
Baton Rouge & 7.6 \\
Houma & 7.1 \\
Lafayette & 7.5 \\
Lake Charles & 8.6 \\
Monroe & 7.5 \\
New Orleans & 7.7 \\
Shreveport/Bossier City & 7.5 \\
Average & 7.6 \\
\hline
\end{tabular}

Source: Statistisches Jahrbuch der Bundesrepublik Deutschland (1999) and Louisiana Department of Labor.

gration and labor/capital mobility. Recalling Mundell, capital mobility and goods-market integration can be seen as substitutes for labor mobility. These two mechanisms can force labor costs into line with no active migration, and therefore with no additional fiscal burdens. If this does not happen, firms will exit and jobs will be destroyed until equilibrium is reached. It is useful to remind ourselves that the demand for labor is not inelastic in the medium to long run; the Marshall-Hicks rule predicts that capital mobility and product market competition increase the elasticity of labor demand, and put more pressure on governments to design employmentfriendly social safety policies. Rather than as racing to the bottom, the examples of Italy and Belgium could be interpreted as prudent reactions to tightening fiscal constraints as tax-driven labor-cost wedges raise unemployment levels (increasing costs of social security) and lower the tax base (due to the destruction of jobs). It turns out, incidentally, that evidence for a race to the bottom in the EU remains scanty, as documented in Bertola, Boeri, and Nicoletti (2001). 
Third, I thought the authors were not attentive enough to the growing importance of European pensions' third pillar (i.e., private provisions), which can be seen as (1) a tacit mechanism for scaling back redistribution in the system (first pillar), and (2) a driving force for the transferability of pensions. The third pillar may involve many more families in Europe than in the United States, because European household saving rates are significantly higher. One reason frequently given for the boom in European stock markets during the late 1990s is that households are taking note of these problems and are acquiring shares as insurance against future shortfalls in the public pension system.

Fourth, the authors focus too much on redistribution in my view and not enough on the size of the pie. The most important life-savers of pension systems are economic growth and concomitant labor force participation. David Wise, in his work with Gruber and others, documents a strong negative correlation between effective taxation and labor force participation, especially among older men just before retirement. Examples from Holland, Denmark, and Ireland support this point. The possibility that both could be jointly endogenous is real and has been demonstrated in Eastern Europe, where unemployment of older workers with unsuitable human capital for a market economy was reduced by massive early retirement (Hungary and East Germany are prominent examples). Governments faced limited financing options for this policy because the profits of state enterprises were no longer available and income taxes were not yet implemented. They ended up taxing labor at rates that correspond to the higher end of OECD (Organization for Economic Cooperation and Development) Europe (Boeri, Burda, and Köllö 1998). This makes it clear that early retirement as a mechanism of redistribution is a slippery slope that can lead to a low participation, high tax, and high unemployment equilibrium, making the region or nation a potential candidate for handouts from the EU-hardly a palatable option.

Finally, although the paper makes a number of important claims, I cannot hide my disappointment at the poor documentation of the empirical extent of migration's effect on pensions (i.e., the lack of hard tables and figures). The migration numbers, although low, must still provide some support for the authors' arguments about increasing mobility among the young, the educated, the non-EU nationals, and so on, which are presented in the paper without any quantitative evidence. It was disappointing that one of the key predictions of the paper-that mobility among economies with dominant first-pillar systems should be significantly higher than among less coordinated and harmonized countries emphasizing second-pillar systems - was never put to an econometric test, although this would have been rather straightforward. 


\section{References}

Bertola, G., T. Boeri, and G. Nicoletti (eds.). 2001. Welfare and employment in a united Europe. Cambridge, Mass.: MIT Press.

Boeri, T., M. Burda, and J. Köllö. 1998. Mediating the transition: Labor markets in Central and Eastern Europe. EPI Report No. 4. London: CEPR.

Faini, R., and A. Venturini. 2000. Home bias and migration. Unpublished manuscript, University of Torino, Italy.

Mundell, R. 1957. International trade and factor mobility. American Economic Review 51:321-55.

\section{Discussion Summary}

Horst Siebert proposed to distinguish two organizational issues, namely, how to organize the schemes of insurance and how to define membership in these schemes. With respect to the first issue, he argued that especially in the first pillar the territoriality principle, that is, organization on a national basis, would be the only viable option, because a pan-European method of social insurance would be too complicated. As to the question of who should be a mandatory member in the first-pillar system, he suggested that one think of applying the Cassis-de-Dijon verdict to the national insurance schemes, at least as an intellectual device, in order to show the impact. Such a regime would mean that individuals could choose to which national systems they want to belong. This, according to Siebert, would probably result in adjustments of the national systems and reduced heterogeneity, because the systems could not stand the mobility of people. He added that uncoupling the pensions from the work contract, in the sense that pensions would be related to contributions and not to earnings, would increase the flexibility of the system under the European concept, provided contributors accrued rights in the first and second pillars that they can take along across national borders. Siebert noted that taking along the rights could require subsidies defined on the EU level, but that one should be careful not to open up a new category of subsidies in order to increase the mobility of people.

Martin Feldstein remarked that switching between two national systems seems to be a very complicated issue, partly because the systems are not proportional. He wondered why the solution toward a pan-European pension system is not to have defined contribution (DC) plans. As an illustration of how to avoid the problems of mobility, he argued that in a system with notional DC plans, people working in each country made contributions to their account and in the end each government would pay benefits based on the years that were contributed and on the notional rate of return 
that people are entitled to in their notional defined contribution system. Pierre Pestieau replied that the way benefits are computed in the case of cross-border mobility is quite fair and that there is not much room for strategic mobility. Alain Jousten added that, although portability would obviously be improved by introducing DC plans, problems would not be resolved altogether because DC plans are also usually interwoven with different parts of the tax code in the different countries.

Assar Lindbeck pointed out that the argument that grandfathers should pay because they were overcompensated confronts the dilemma that there is a trade-off between good rules and stable rules. Even if it was a mistake to design pension systems in a way that old generations receive six times what they paid in many countries, it would be problematic to change the rules when people reach sixty-five years of age, because many persons might have based their past economic decisions on those rules. He suggested one take into account the fact that rules may be bad, but stable rules have an advantage in society. Edward Palmer remarked that one reason for overcompensating old generations in our systems has been that many of them went through two world wars, a depression, and so forth. He noted that this era has passed and that Sweden has moved to notional accounts and financial accounts only, adding that he sees no reason why that type of combination could not be employed all over Europe. Alain Jousten responded that the focus should not only be justice toward the old generation, but also justice toward the young generation, which would justify levying at least some of the burden on the old generations as well. $\mathrm{He}$ agreed only to some degree to the argument of a free lunch as compensation for two world wars, as he noticed that in many countries high-income workers were compensated more for the war than low-income workers.

Assar Lindbeck questioned the proposition in the paper that redistribution should be centralized on a European level and suggested that people should be allowed to vote with their feet. John McHale remarked that in the real world the redistribution that takes place is determined in the political process, and that it is easy to write down political economy models in which the amount of redistribution taking place is excessive relative to any given social welfare function. In such a framework, he argued, mobility can act as a disciplining device, promoting a better social welfare outcome and, consequently, it is not self-evident that redistribution should move to the central level. Pierre Pestieau answered that the paper simply reproduces the state of the art in public finance and that he would not endorse any kind of harmonized social security system.

Axel Börsch-Supan argued that the problems of mobility are much easier to handle under a funded system than in a pay-as-you-go (PAYGO) system, simply because in a funded system there is capital that one can take along much more easily than the claims on human capital. $\mathrm{He}$ stressed that the current social security wealth in a funded system is always 
well defined, whereas the current social security wealth in an unfunded system is always ill defined even in a notional account system, essentially because the markets are different. He added some qualifications, namely that while portability of corporate pensions in the Netherlands was enforced recently, firm pensions in Germany are still often not portable at all, particularly in the reserve account system. He called for regulations to foster portability, because this could not be left to the market due to a complicated game of stick and carrot between employer and employees, as well as the interest employers have to bind workers to their company. Ignazio Visco also emphasized the importance of regulating the portability of pensions, which could be accomplished at the central European level, and stressed that increasing competition between open funds rather than closed occupational funds would have very positive effects. Martin Feldstein questioned the necessity of regulation and argued in favor of freedom of private agents to contract in any way they want.

David $A$. Wise noted that twenty years ago in the United States most firm pensions were defined benefit (DB) pensions with provisions not unlike those in the social security systems in Europe and with a considerable degree of variation. He reported that while these different provisions do not seem to have had a major impact on job choice, they seem to have been important with respect to mobility later on, typically encouraging employees to stay until some retirement age and giving an enormous incentive to leave afterward. Based on the evidence that twenty years later at least three-fourths of contributions to pension funds go to DC plans that have none of these incentive effects with respect to mobility, he concludes that limitations on the freedom of choice have been removed.

The importance of the federal issue was emphasized by Georges de Menil, who argued that it might become one of the major forces pushing European pension reform ahead. He noted that in a situation of system competition there is always the choice either to collude, which means centralized regulation, or to compete. Although, due to limited actual labor mobility, only a few people might be involved, he argued that the institution of the European Court of Justice can be expected to force governments to change regulations that represent obstacles to mobility and violate the European treaties. He added that labor mobility is not necessary to induce institutional competition but that it is sufficient to have capital mobility, which undisputably is realized, at least since the monetary union. Assar Lindbeck raised the issue that when looking at the low incidence of labor mobility in Europe it is necessary to look at the microeconomic incentives and that a situation is not reasonable in which contributions to a pension system in one country are lost when people move to another country. He proposed a system in which it is possible for an individual to carry his compulsory retirement savings with him. Lindbeck added that in his view the discussant underestimates the extent of labor mobility in the 
United States in view of different welfare payments, as it is very difficult to explain the flooding from southern states in the United States to some northern large cities like New York from one unemployment situation to another without emphasizing that the welfare payments are five or six times as high in the state of New York as in Louisiana. The notion of very low labor mobility in Europe was challenged by Axel Börsch-Supan, who argued that in addition to the regional mobility — which might change in the future as well - there is the dimension of sectoral mobility within a region, which is of greater and increasing importance. Given that people are expected to move increasingly between different jobs, he argued in favor of a funded system, because patchwork life histories are much easier to accommodate here than in a PAYGO system.

As an illustration of what may come about in some countries in Europe, Jeffrey Liebman reported on the evidence in the United States with respect to the distributional implications of immigration, stating that the group that currently gets the highest rate of return in the Social Security system are Hispanic Americans, because disproportionally they are immigrants that come into the United States part of the way through their career. As a reaction to this, there had been a lot of pressure to reduce the benefits that are available to the immigrants. Pierre Pestieau observed that not only actual mobility but also the threat of mobility matters and noted that in a pure symmetric Nash equilibrium, mobility has an impact even if no one moves. He also endorsed the view that capital mobility is a kind of substitute, and underlined the conclusion in the paper that as a result there is a drive toward less PAYGO and less redistribution. 